\title{
Knowledge and practice of birth preparedness and complication readiness among pregnant women in Kano, Nigeria
}

\author{
Ayyuba Rabiu, ${ }^{1}$ Habiba Isah Ladu ${ }^{2}$ \\ ${ }^{1}$ Department of Obstetrics and Gynecology, Bayero University Kano, Aminu Kano Teaching Hospital; \\ ${ }^{2}$ Community Acquired Pneumonia and Invasive Bacteremic Disease Project, Aminu Kano Teaching \\ Hospital, Kano State, Nigeria
}

\begin{abstract}
Knowledge of birth preparedness and complication readiness in pregnant women is the process of planning for safe delivery and anticipating the action needed in case complications arise. This study was aimed at determining the knowledge of birth preparedness and complication readiness, among pregnant women attending antenatal clinic in Murtala Muhammad specialist hospital, Kano. A descriptive cross-sectional design was used. Data was collected using interviewer administered structured questionnaire from 394 pregnant women attending ante-natal clinic. The questions elicited pregnant women's socio-demographic characteristics, knowledge of birth preparedness and complication readiness, and the factors that influence them. Data were analyzed using SPSS version 19 Computer Software. Three hundred and ninetyfour pregnant women were recruited within the period. The mean age \pm SD was $26.9 \pm 6.21$ years. Two hundred and ninety-four pregnant women $(75.8 \%)$ were aware of the concept of birth preparedness, while $94(24.2 \%)$ were oblivious. A larger proportion of the respondents $237(60.2 \%)$ had the opinion that women can save money to prepare for birth, while $75(19.0 \%)$ believed women should identify mode of transport as part of birth preparedness.
\end{abstract}

Correspondence: Ayyuba Rabiu, Department of Obstetrics and Gynecology, Bayero University Kano/Aminu Kano Teaching Hospital, P.M.B. 3011, Kano, Kano State, Nigeria.

Tel.: 08055559473.

E-mail: ayyubarabiu@yahoo.com

Key words: Birth preparedness, complication readiness, ante-natal clinic, Nigeria.

Contributions: the authors contributed equally.

Conflict of interest: the authors declare no potential conflict of interest.

Funding: none.

Received for publication: 4 August 2018.

Revision received: 15 June 2019.

Accepted for publication: 15 June 2019.

This work is licensed under a Creative Commons Attribution NonCommercial 4.0 License (CC BY-NC 4.0).

CC Copyright: the Author(s), 2019

Licensee PAGEPress, Italy

Annals of African Medical Research 2019; 2:38

doi:10.4081/aamr.2019.38
Majority of the pregnant women 96 (54\%) revealed that their community provides them with transport services as part of assistance during child birth. Educational status is associated with knowledge of birth preparedness $(\chi 2=4.081, \mathrm{P}=0.05)$. The study revealed that there is fair knowledge of birth preparedness and complication readiness and saving money was the commonest birth preparedness practice known among the respondents.

\section{Introduction}

Knowledge of birth preparedness and complication readiness in pregnant women is the process of planning for safe delivery and anticipating the action needed in case complications arise. It promotes active preparation and decision making for delivery by pregnant women and their families. ${ }^{1}$

Birth preparedness and complication readiness (BPCR) is the advance planning and preparation for delivery, which can do much to improve maternal health outcomes. BPCR helps ensure that women can reach professional delivery care when labor begins. In addition, birth preparedness and complication readiness can help reduce the delays that occur when women experience obstetrics complications, such as recognizing the complications and deciding when to seek care, reaching a facility where skilled care is available and receiving care from qualified providers at the facility. Life threatening complications can also occur in early post-partum; birth preparedness and complication readiness should also include preparing/planning for accessing post-partum care during the first week after delivery and at six weeks after delivery. ${ }^{2}$

Pregnancy and child birth are normal physiologic events, and the desire for every family at the end is to have a healthy mother and a healthy baby, and when this happens, pregnancy can be regarded as a joyful event. Yet for many women childbearing is experienced not as the joyful event as it should be.

Over the past few decades, there was a great strides towards improvement of women's health; more than a decade has been added to life expectancy, and fertility rates in both developed and developing countries have declined substantially, helping to reduce burdens associated with childbirth and child rearing. ${ }^{3}$ Despite this progress, more than half a million women, $99 \%$ of whom live in the developing world continue to die yearly in pregnancy and childbirth due to entirely preventable reasons. ${ }^{4}$

A BPCR plan should include identification by the pregnant woman the following elements; the desired place of birth, the preferred skilled birth attendant, the location of the appropriate closest health facility, funds for birth and related obstetrics emergency, a decision maker during birth process, a birth companion, prepare important supplies for the care of the newborn, support in looking after the home and children while the woman is away, transport to health facility for birth, transport in case of an emergency and identification of compatible blood donor, being aware of an 
expected date of delivery, and on the key obstetrics danger signs. ${ }^{4}$

The aim of this study was to determine the knowledge of birth preparedness and complication readiness, among pregnant women attending antenatal clinic in Murtala Muhammad specialist hospital (MMSH), Kano.

\section{Materials and Methods}

It was a descriptive cross-sectional survey that was conducted in Murtala Muhammad Specialist Hospital (MMSH), Kano from $12^{\text {th }}$ December 2017 to $31^{\text {st }}$ March, 2018, among 394 pregnant women attending antenatal clinic. A structured pre-tested open and closed ended questionnaire was administered among consenting pregnant women. This was adopted from a semi-structured interviewer administered questionnaire in a research titled Monitoring birth preparedness and complication readiness. ${ }^{5}$ Information such as socio-demographic and reproductive characteristics of respondents, knowledge and practice of women on birth preparedness and complication readiness was recorded.

The sampling technique used was systematic random probability technique to obtain data from pregnant women attending antenatal clinic in MMSH, until the desired sample size was obtained. The sampling frame consisted of the entire clients attending antenatal clinic that were eligible for the study. Using a systematic random sampling, ${ }^{6}$ every $3^{\text {rd }}$ client was chosen until the required sample size was obtained.

An extensive literature review was done and the questionnaire was obtained from previously used tools of similar studies. The questionnaire was reviewed to ensure its validity.

Data were collected using an interviewer administered questionnaire, translated verbally to Hausa language to clients who did not understand English language in which the questionnaire was prepared, for their easy understanding. The purpose and procedure was clearly explained to the clients, and then an informed consent was obtained from each individual client that was used for the study. The researcher and the research assistants, who were trained on the use of the instruments, asked the clients questions and the clients chose from the options provided.

The data collected were analyzed using SPSS version 19 computer software (IBM SPSS Statistics Inc., IL, Chicago, USA). Quantitative variables were summarized using measures of central tendency and measures of variability. Qualitative variables were summarized as frequencies and percentages. A $\chi 2$ test was used for categorical variables. A $P$ value of $\leq 0.05$ was considered statistically significant.

Ethical approval was obtained at the Kano state Ministry of health, and approval from the department of obstetrics and gynecology, MMSH.

In this survey, Birth Preparedness referred to plan to have a safe (normal) delivery by identifying a place of birth, means of transportation, saving money for delivery expenses and identifying a birth attendant; and Complication Readiness meant being ready and having measures to tackle pregnancy problems and emergency.

\section{Results}

The survey was conducted in Murtala Muhammad Specialist Hospital (MMSH), Kano from $12^{\text {th }}$ December 2017 to $31^{\text {st }}$ March, 2018. Three hundred and ninety-four pregnant women were recruited within the period. The mean age $\pm \mathrm{SD}$ was $26.9 \pm 6.21$ years. The median age was 26.0 years. The age range was from 15 to 47 years.

The average number of pregnancies and child birth were $4.9 \pm 3.44$ and $3.4 \pm 2.94$ respectively. The average number of living children and antenatal care visits for the index pregnancy were $2.8 \pm 2.62$ and $1.8 \pm 1.49$

Two hundred and ninety-four pregnant women (75.8\%) have heard of birth preparedness while 94 (24.2\%) have not heard of birth preparedness

Majority of the respondents were married 378 (95.9\%), Hausas 300 (76.3\%) and Muslim 375 (95.2\%) (Table 1). A significant number of the respondents attended secondary school 167 (42.6\%) and were home managers 226 (57.7\%). Their husband's occupation was mainly business $173(46.0 \%)$ with a few unemployed 9 (2.4\%) (Table 1).

A larger proportion of the respondents 237 (60.2\%) had the opinion that women can save money to prepare for birth, while 75 $(19.0 \%)$ believed women should identify mode of transport as part of birth preparedness (Figure 1). Majority of the pregnant women $96(54 \%)$ revealed that their community provides them with transport services as part of assistance during child birth. Other services

Table 1. Socio demographic characteristics of the respondents.

\begin{tabular}{|c|c|c|}
\hline Variable & Frequency & Percent \\
\hline $\begin{array}{l}\text { Marital status } \\
\text { Married } \\
\text { Widowed } \\
\text { Total }\end{array}$ & $\begin{array}{c}378 \\
16 \\
394\end{array}$ & $\begin{array}{c}95.9 \\
4.1 \\
100.0\end{array}$ \\
\hline $\begin{array}{l}\text { Tribe } \\
\text { Hausa } \\
\text { Fulani } \\
\text { Yoruba } \\
\text { Igbo } \\
\text { Others } \\
\text { Total }\end{array}$ & $\begin{array}{c}300 \\
51 \\
10 \\
10 \\
22 \\
393\end{array}$ & $\begin{array}{c}76.3 \\
13.0 \\
2.5 \\
2.5 \\
5.6 \\
100.0\end{array}$ \\
\hline $\begin{array}{l}\text { Religion } \\
\text { Islam } \\
\text { Christianity } \\
\text { Others } \\
\text { Total }\end{array}$ & $\begin{array}{c}375 \\
18 \\
1 \\
394\end{array}$ & $\begin{array}{c}95.2 \\
4.6 \\
0.3 \\
100.0\end{array}$ \\
\hline $\begin{array}{l}\text { Educational status } \\
\text { Primary } \\
\text { Secondary } \\
\text { Tertiary } \\
\text { Islamiyya/Qur'anic } \\
\text { None } \\
\text { Total }\end{array}$ & $\begin{array}{c}84 \\
167 \\
53 \\
70 \\
18 \\
394\end{array}$ & $\begin{array}{c}21.4 \\
42.6 \\
13.5 \\
17.9 \\
4.6 \\
100.0\end{array}$ \\
\hline $\begin{array}{l}\text { Occupation (wife) } \\
\text { Home manager } \\
\text { Executive } \\
\text { Business } \\
\text { Artisan } \\
\text { Student } \\
\text { Others } \\
\text { Total }\end{array}$ & $\begin{array}{c}226 \\
9 \\
76 \\
45 \\
4 \\
32 \\
382\end{array}$ & $\begin{array}{c}57.7 \\
2.3 \\
19.4 \\
11.5 \\
1.0 \\
8.2 \\
100.0\end{array}$ \\
\hline $\begin{array}{l}\text { Husband's occupation } \\
\text { Executive } \\
\text { Business } \\
\text { Unemployed } \\
\text { Artisan } \\
\text { Student } \\
\text { Others } \\
\text { Total }\end{array}$ & $\begin{array}{c}68 \\
173 \\
9 \\
58 \\
5 \\
63 \\
376\end{array}$ & $\begin{array}{c}18.1 \\
46.0 \\
2.4 \\
15.4 \\
1.3 \\
16.8 \\
100.0\end{array}$ \\
\hline
\end{tabular}


that were provided were blood donation $45(25 \%)$ and ways to get money to help family for birth 34 (19.0\%) (Figure 2).

An alarming figure of $314(80.5 \%)$ strongly agreed a woman should plan ahead of time where she will give birth to her baby. Also, $263(67.3 \%)$ pregnant women agreed a woman should plan ahead of time how she will get to the place where she will give birth (Table 2).

Up to $196(50.1 \%)$ of the pregnant women agreed it is not necessary for a husband/partner to accompany his wife to antenatal care visits. Conversely, 273 (72.8\%) of the respondents disagreed with the statement "when women do not go to health facility to give birth, it's mainly because it is too expensive". Similarly, 291 $(74.2 \%)$ disagreed with the statement "when women do not go to health facility to give birth, it's mainly because the staff there do not treat women respectively".

A staggering figure of $178(45.8 \%)$ agreed that it is not necessary for a husband/partner to accompany his wife when she is giving birth. However, 204 (52.3\%) of the respondents disagreed that giving birth is mostly a woman's matter; husbands/partners have little to contribute.

There were no statistically significant associations between knowledge of birth preparedness and their age group $(\chi 2=6.341$, $\mathrm{P}=0.278$ ), occupation ( $\chi 2=6.069, \mathrm{P}=0.298)$, Husband's occupation $(\chi 2=10.047, \mathrm{P}=0.072)$ respectively. However, educational status was associated with knowledge of birth preparedness $(\chi 2=4.081$, $\mathrm{P}=0.05$ ) (Table 3).

A larger proportion of the respondents spoke with someone outside of health facility about where they should give birth to their baby $243(63.0 \%)$ and making arrangements for funds/finances 225 (58.4\%). However, only $130(34.0 \%)$ spoke with anyone outside of health facility about arrangement for blood donor. More than half of the respondents, spoke with health care professional outside of health facility for the delivery of the index pregnancy $212(55.8 \%)$ and had arranged with a family member for the delivery $220(57.3 \%)$, respectively. Also, $372(94.9 \%)$ planned to have their health checked after delivery (Table 4).

Husbands were mostly involved in the decision making about the delivery of the baby 211 (85.5\%), funds/finances $214(93.9 \%)$, blood donor $117(87.3 \%)$, where to give birth $282(74.6 \%)$ and health care professional $199(93.0 \%)$ to attend to (Table 5).

A staggering figure of $305(78.0 \%)$ planned to deliver their baby in government hospital, $235(62.0 \%)$; expected their birth to be assisted by doctors and $364(98.9 \%)$ planned to have their postnatal checkup in government hospitals.

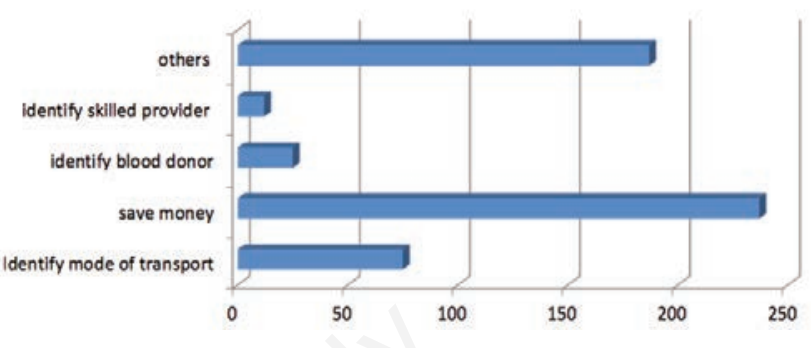

Figure 1. Women's opinion on what they should do for birth preparedness.

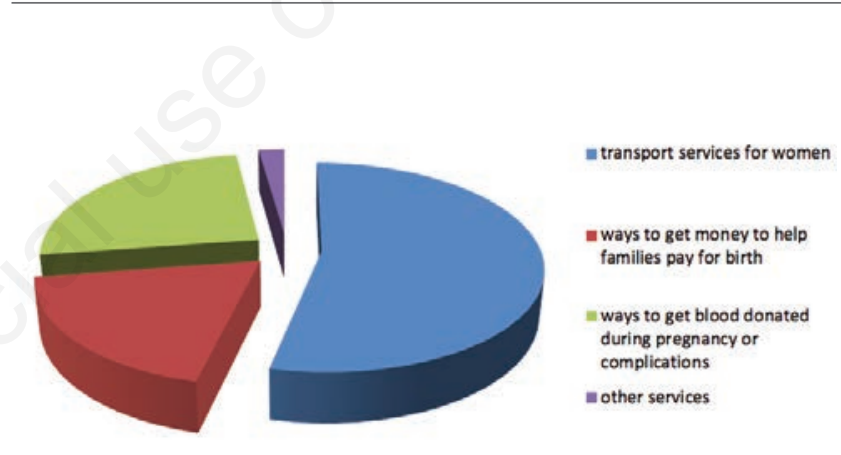

Figure 2. Reported Provision of Community Services for Pregnant women towards Birth Preparedness.

Table 2. Knowledge and practice of women on birth preparedness and complication readiness.

\begin{tabular}{|c|c|c|c|c|c|}
\hline Variable & Strongly agree (\%) & Agree (\%) & Undecided (\%) & Disagree (\%) & Strongly disagree (\%) \\
\hline $\begin{array}{l}\text { A woman should plan ahead of time } \\
\text { where she will give birth to her baby }\end{array}$ & $314(80.5)$ & $60(15.4)$ & $13(3.3)$ & $3(0.8)$ & - \\
\hline $\begin{array}{l}\text { A woman should plan ahead of time } \\
\text { how she will get to the place where } \\
\text { she will give birth }\end{array}$ & $83(21.2)$ & $263(67.3)$ & $14(3.6)$ & $31(7.9)$ & - \\
\hline $\begin{array}{l}\text { It is not necessary for a husband/partner } \\
\text { to accompany his wife to ante } \\
\text { natal care visits }\end{array}$ & $26(6.6)$ & $196(50.1)$ & $20(5.1)$ & $134(34.3)$ & $15(3.8)$ \\
\hline $\begin{array}{l}\text { When women do not go to health } \\
\text { facility to give birth, } \\
\text { its mainly because it is too expensive }\end{array}$ & $13(3.5)$ & $72(19.2)$ & $7(1.9)$ & $273(72.8)$ & $10(2.7)$ \\
\hline $\begin{array}{l}\text { When women do not go to health facility } \\
\text { to give birth, its mainly because the staff } \\
\text { there do not treat women respectively }\end{array}$ & $6(1.5)$ & $63(16.1)$ & $13(3.3)$ & $291(74.2)$ & $19(4.8)$ \\
\hline $\begin{array}{l}\text { It is not necessary for a husband/partner } \\
\text { to accompany his wife when she is given birt }\end{array}$ & $15(3.9)$ & $178(45.8)$ & $4(1.0)$ & $166(42.7)$ & $26(6.7)$ \\
\hline $\begin{array}{l}\text { Giving birth is mostly a woman's matter; } \\
\text { husbands/partners have little to contribute }\end{array}$ & $5(1.3)$ & $141(36.2)$ & - & $204(52.3)$ & $40(10.3)$ \\
\hline
\end{tabular}


When prompted, it was discovered that the arrangements made by the respondents for the delivery of their index pregnancy were to identify mode of transport, followed by saving money, identification of skilled birth attendants or blood donor (Figure 3).

\section{Discussion}

The overall mean age was $26.9 \pm 6.21$ years with a median age of 26.0 years. This is similar to a study conducted in Northern Nigeria among women of child bearing age (15-49 years) by Okereke et $a l^{7}$ on Knowledge of safe motherhood and implications for maternal mortality reduction. This can be explained by similarity in cultural believes of the Northern Nigeria states, where the women get married and bear children at an early age.

The respondents were largely Hausas (76.3\%) and Muslims (95.2\%). This ethnic and religious composition reflects a typical Kano settlement where majority of the indigenes are Hausa-Fulani and Muslims. A similar study in Northern Nigeria revealed same findings. ${ }^{8}$ Up to $42.6 \%$ of the respondents attended secondary school, while only $13.5 \%$ attended tertiary school; $4.6 \%$ had no form of education. Similar findings were obtained in studies conducted in Northern Nigeria. ${ }^{9}$ This can be explained by the fact that

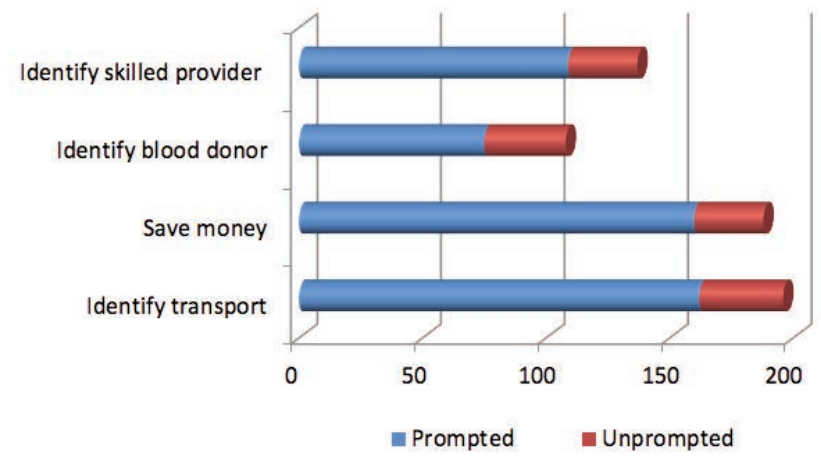

Figure 3. Arrangements made by the respondents for the birth of their index pregnancy.

Table 3. Cross tabulation between knowledge of birth preparedness and some socio demographic characteristics.

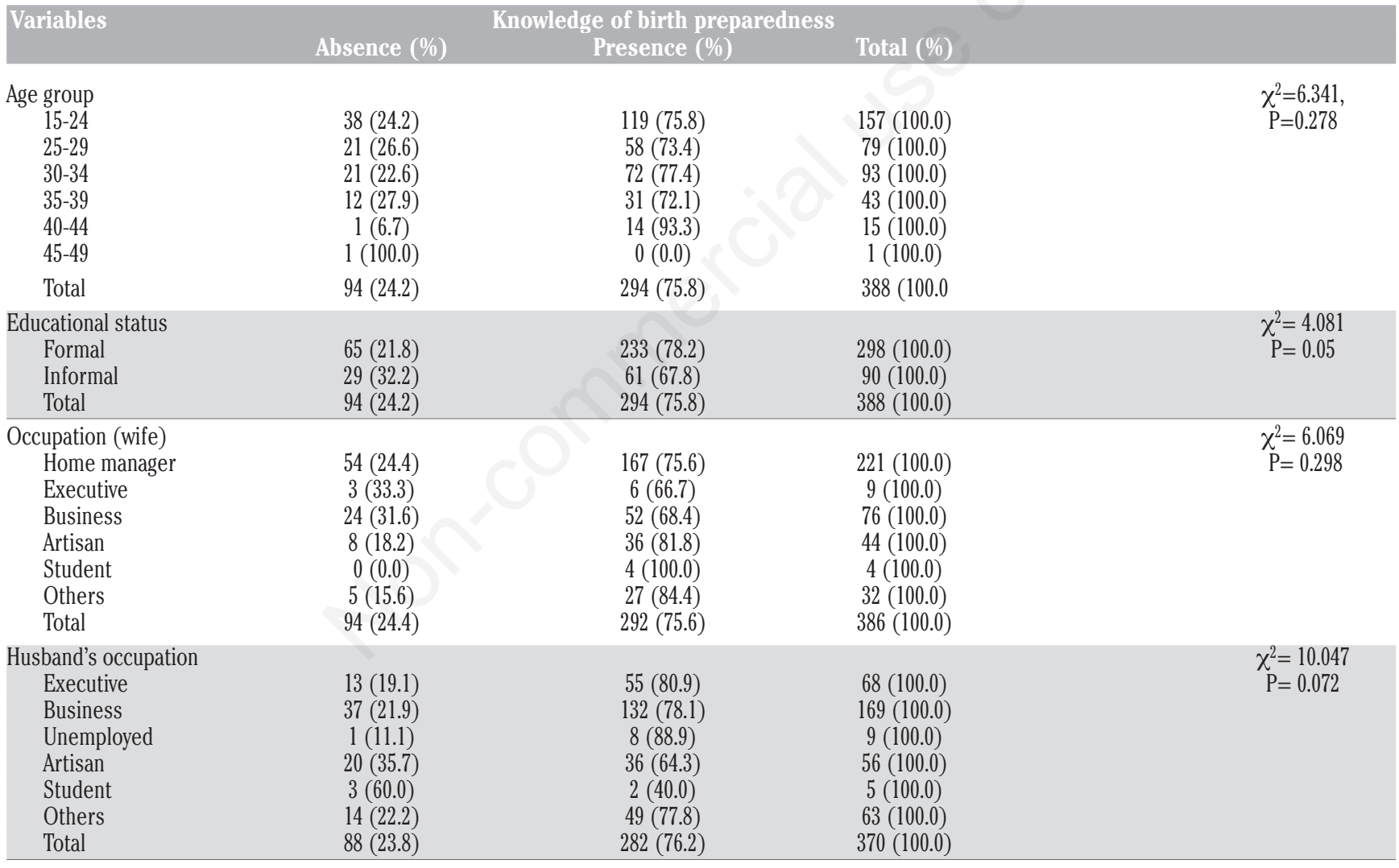

Table 4. Information on birth preparedness and complication readiness.

\begin{tabular}{|c|c|c|c|}
\hline Feature & Yes $(\%)$ & No $(\%)$ & $\begin{array}{c}\text { Responses } \\
\text { I don't know (\%) }\end{array}$ \\
\hline Did you speak with anyone outside of health facility about where you should give birth to your baby? & $243(63.0)$ & $142(36.7)$ & $1(0.3)$ \\
\hline Did you speak with anyone outside of health facility about arrangements for funds/finances? & $225(58.4)$ & $158(41.0)$ & $2(0.6)$ \\
\hline Did you speak with anyone outside of health facility about arrangements for blood donor? & $130(34.0)$ & $251(65.7)$ & $1(0.3)$ \\
\hline Did you speak with anyone outside of health facility for health care professional to deliver your baby? & $212(55.8)$ & $167(44.0)$ & $1(0.2)$ \\
\hline Have you or your family members made arrangements for the birth of this child? & $220(57.3)$ & $161(41.9)$ & $3(0.8)$ \\
\hline Are you planning to have your health checked after delivery? & $372(94.9)$ & $20(5.1)$ & $0(0.0)$ \\
\hline
\end{tabular}


most women in Northern Nigeria do not enroll in western education, and even when they do, they usually end at secondary school level. The 2014 MDG survey revealed the literacy level in North Western Nigeria was $35.0 \%$, compared to that in South East $93.5 \% .^{10}$

Majority of the respondents were home managers (57.7\%), $11.5 \%$ were artisans, while only $2.3 \%$ were civil servants. This finding is similar to other northern Nigeria studies. ${ }^{9,11}$ This can be explained by the fact that men are believed to be the only breadwinners of the family especially in northern Nigeria. The women are mostly not gainfully employed; they are allowed to stay at home to take care of the family.

The mean gravidity was $4.9 \pm 3.44$ and the mean parity was
$3.4 \pm 2.94$.This is not surprised; a study in northern Nigeria also reported a mean gravidity of 6.7 , and mean parity of 5.7 .8 This shows the high fertility rate in northern Nigeria which can be explained by poor contraceptive use in our region. The current fertility rate in North Western Nigeria is 5.5.12

The average number of antenatal visits was $1.8 \pm 1.49$. In a study in Kenya, ${ }^{13}$ about half of women in rural and urban settings (52.2\% and $49.2 \%$, respectively) attended antenatal clinics only once. The ante-natal clinic (ANC) coverage for North Western Nigeria according to 2014 MDG survey was $38.1 \%$, which is low, compared to South West with ANC coverage of $78 \%{ }^{10}$

In this study majority of the respondents $(75.8 \%)$ were aware of the concept of birth preparedness. Their awareness is more than

Table 5. Birth plans of the respondents.

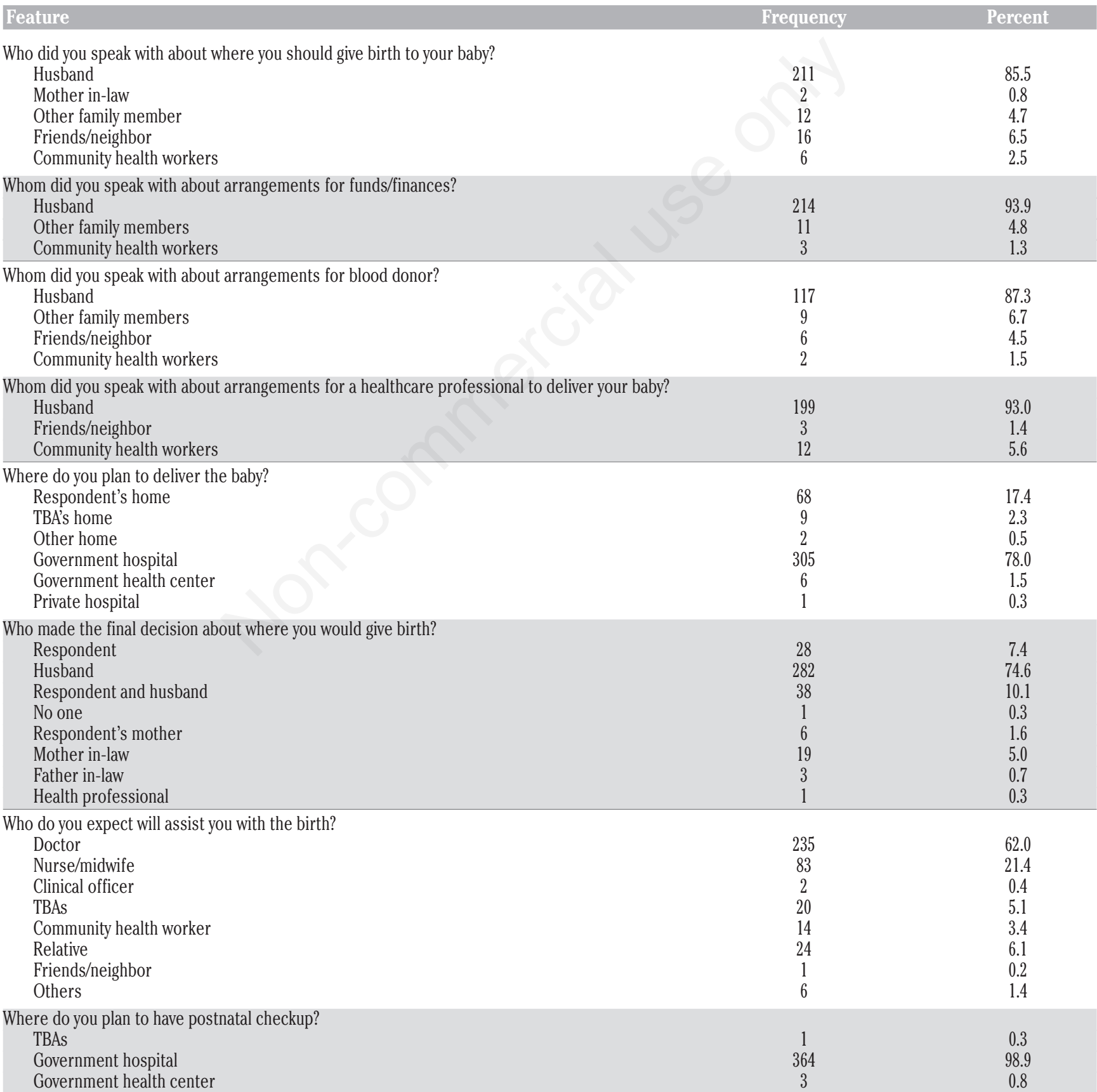


the figure of $48.4 \%$ reported among rural community of Edo State, Nigeria $^{14}$ and $61 \%$ reported among antenatal clinic attendees in Ile-ife. ${ }^{15}$

More than half of the respondents $(60.2 \%)$ knew saving money as a form of birth preparedness and complication readiness; this is similar to a study in Ile-Ife where $64.8 \%$ were saving money towards delivery. ${ }^{15}$ The figure is also similar to the $57 \% \%$ reported in the rural community of Edo State. ${ }^{14}$ Only a few of the respondents knew making plans for transportation (19.0\%), making arrangements for blood donor (6.3\%), and identifying a skilled provider $(3.0 \%)$ as forms of birth preparedness and complication readiness. This is similar to the findings of Iliyasu et al. ${ }^{16}$ in Northern Nigeria. This is not surprising as both studies were conducted in northern part of Nigeria where more priority is given to making plans for naming ceremonies, buying cloths for mother and baby, rather than critical components of birth preparedness such as making plans for skilled attendants, identifying blood donor and transportation.

In this study only $57.3 \%$ had made arrangements for the delivery of their baby. This similar to the result of a study in Ile-Ife where $61 \%$ of women made arrangements for delivery of their babies. ${ }^{15}$ Out of all the respondents when prompted, $41.1 \%$ identified mode of transport, $40.6 \%$ saved money, $34.6 \%$ identified skilled provider, and $27.4 \%$ identified blood donor. This findings are lower than the findings in Uganda. ${ }^{17}$ The most common birth preparedness practice from above is saving money. This can be explained by the fact that money is required to facilitate referral in case of emergencies. Another reason why money is the commonest birth preparedness in our area is for preparation of naming ceremonies, buying of baby cloths and delivery materials.

This study also showed that the assistance provided by various communities of the respondents was encouraging; transportation (54\%), blood (25\%), and finance (19\%).

More than half of the respondents $(72.8 \%)$ did not consider cost of services, and $74.4 \%$ did not consider maltreatment by hospital staff as a deterrent to maternal care utilization. This is in contrast to the findings in India ${ }^{18}$ and Nepal ${ }^{19}$ where cost of services and distance were barriers to accessing maternal care. The reason why cost of services might not be a deterrent for accessing maternal services might be due to the free maternal services offered in secondary and primary health care centers in Kano state of Nigeria. $^{20}$

The study showed that $42.7 \%$ of the respondents disagreed on husband's company during delivery. This is similar to a study in Northern Nigeria where most of the respondents disagreed on husband's company during delivery. ${ }^{16}$ This could be explained by similarities in cultural factors in Northern Nigeria where men do not actively participate in maternity care.

The final decision makers showed by the study were the respondent's husband $(85.5 \%)$, this is similar to the study conducted in Northern Nigeria where men were the major decision makers on the process of birth preparation, they decide on when and where to seek care. ${ }^{16}$

In this study majority of the respondents $(94.9 \%)$ agreed to attend post-natal checkup, irrespective of where they deliver. A study in Northern Nigeria revealed that only $11.4 \%$ of those who received ANC returned for a postnatal check after 6 weeks. ${ }^{8}$

The study revealed there were no statistically significant associations between knowledge of birth preparedness and their age group $(\chi 2=6.341, \mathrm{P}=0.278)$, occupation $(\chi 2=6.069, \mathrm{P}=0.298)$, Husband's occupation $(\chi 2=10.047, \mathrm{P}=0.072)$ respectively. However, educational status was associated with knowledge of birth preparedness $(\chi 2=4.081, \mathrm{P}=0.05)$. A similar study in Ethiopia and Kenya revealed high level of education was associated with increased birth preparedness practices. ${ }^{21,22}$ A study in Ethiopia revealed that Women with primary education and above were identified to be twice more likely to be prepared and ready for birth and complications. ${ }^{22}$

In conclusion, this study revealed that there was fair knowledge of birth preparedness and complication readiness and saving money was the commonest birth preparedness practice known among the respondents. Education was also found to be associated with knowledge of birth preparedness and complication readiness.

We therefore recommend health education on birth preparedness and complication readiness to be targeted to both men and women.

\section{References}

1. Markos D, Bogale D. Birth preparedness and complication readiness among women of child bearing age group in Goba woreda, Oromia region, Ethiopia. BMC Pregn Childbirth 2014; $14: 1-9$.

2. The skilled care initiative; Family Care International. Birth preparedness: An essential part of antenatal care counselling. Birth Preparedness: An Essential Part of ANC Counselling Internet. 2002; Available from: http://www.familycareintl. org/issues/sm_skilled_care.php

3. Grown C, Gupta GR, Pande R. Taking action to improve women's health through gender equality and women's empowerment. Lancet 2005;365:541-3.

4. World Health Organization. Maternal mortality: The Sustainable Development Goals and the Global Strategy for Women's, Children's and Adolescents' Health Internet. 2018. Available from: http://www.who.int/news-room/factsheets/detail/maternal-mortality

5. Roxana C, Barco D. Monitoring birth preparedness and complication readiness: tools and indicators for maternal and newborn health. Internet. 2004. Available from: http://reprolineplus.org/system/files/resources/bpcr_monitoringtools.pdf

6. Singa P. An introductory text to Biostatistics. 2nd ed. Habson Nigeria limited, Zaria: 1996.

7. Okereke E, Aradeon S, Akerele A, et al. Knowledge of safe motherhood among women in rural communities in northern Nigeria: implications for maternal mortality reduction. Reprod Health Internet 2013;10:2-12. Available from: https://doi.org/10.1186/1742-4755-10-57

8. Galadanci H, Ejembi C, Iliyasu Z, Alagh B. Maternal health in Northern Nigeria: a far cry from ideal. BJOG An Int J Obstet Gynaecol 2007;114:448-52.

9. Ekele BA. Gestational age at antenatal clinic booking in Sokoto, northern Nigeria. J Med Sci 1998;27:161-3.

10. National Bureau of Statistics: The Federal Republic of nigeria. The Millenium Development Goals Performance Tracking Survey, 2015 Report. 2015.

11. Ibrahim SA, Galadanci HS, Omale AE. Gestational age at first antenatal attendance in Kano, northern Nigeria. Highl Med Res J 2007;5:75-8.

12. Mberu B, Reed H. NIH Public Access. Popul Rev 2015;53:2346.

13. Delva W, Yard E, Luchters S, et al. A Safe Motherhood project in Kenya: Assessment of antenatal attendance, service provision and implications for PMTCT. Trop Med Int Heal 2010;15:584-91.

14. Ibadin S, Adam V, Adeleye O, Okojie O. Birth preparedness 
and complication readiness among pregnant women in a rural community in southern Nigeria. S Afr J Obstet Gynaecol 2016;22:47.

15. Onayade A, Akanbi O, Okunola H, et al. Birth preparedness and emergency readiness plans of antenatal clinic attendees in Ile-ife, Nigeria. Niger Postgrad Med J 2010;17:30-9.

16. Iliyasu Z, Abubakar I, Galadanci H, Aliyu M. Birth preparedness, complication readiness and fathers' participation in maternity care in a northern Nigerian community. Afr J Reprod Heal 2010;14:21-32.

17. Kabakyenga KJ, Ostergren P, Turyakira E, Petterson KO. Knowledge of obstetrics danger signs and birth preparedness, practises among women in rural Uganda. Rep Heal J 2011;8.

18. Filippi V, Ronsmans C, Campbell O, et al. Maternal health in poor countries: the broader context and a call for action. Lancet 2006;368:1535-41.

19. Dhakal S, van Teijlingen E, Raja E, Dhakal K. Skilled care at birth among rural women in Nepal: Practice and challenges. J Heal Popul Nutr 2011;29:371-8.

20. Galadanci H, Idris S, Sadauki H, Yakasai I. Programs and Policies for Reducing Maternal Mortality in Kano State, Nigeria: A Review. Afr J Reprod Health 2010;14:31-6.

21. Mutiso S, Qureshi Z, Kinuthia J. Birth preparedness among antenatal clients. East Afr Med J 2008;85:275-83.

22. Hailu M, Gebremariam A, Alemseged F, Deribe K. Birth preparedness and complication readiness among pregnant women in Southern Ethiopia. PLoS One 2011;6:1-7. 